\title{
Tecnologias Produtivas, Design e Pesquisa Participativa: Estudo de Caso do Artesanato de Cipó Imbé em Garuva - SC'.
}

\author{
Mauro De Bonis Almeida Simões ${ }^{2}$ \\ ( maurodebonis@udesc.br )
}

\section{Resumo:}

O município de Garuva, situado no extremo norte do Estado de Santa Catarina, destaca-se pelo expressivo número de pessoas envolvidas na produção artesanal de fibras naturais. Uma destas fibras é o Cipó Imbé (Philodendron sp. - ARACEAE), extraído da Mata Atlântica e manufaturado pelos de artesãos de comunidades locais. Através do Planejamento Estratégico Participativo - PEP, realizado pela EPAGRI ${ }^{3}$, identificou-se esta atividade artesanal como uma das principais da economia do município, e a partir daí foi realizada uma pesquisa in loco, sob a forma de um trabalho de conclusão de curso (TCC), que apontou diversas demandas relacionadas ao ciclo produtivo do artesanato e ao design desses produtos. Dentre estas, lista-se a necessidade de reformulação dos processos desta cadeia produtiva, principalmente as etapas de beneficiamento da fibra e o aprimoramento dos mesmos.

Assim, o presente projeto de pesquisa formulou como objetivo central a investigação de conceitos e práticas adequadas, mediante o uso de metodologias de pesquisa participativa consagradas, a melhoria das tecnologias produtivas e os respectivos produtos artesanais de cipó Imbé na comunidade de Palmital. Este projeto de pesquisa é apoiado pelo Governo de Santa Catarina (Projeto Microbacias 2 / EPAGRI), pois é um dos dez "Projetos Faróis" de experimentação de pesquisas participativas em curso no Estado, diretamente relacionado à pesquisa e aprimoramento de produtos e tecnologias baseadas no saber local e conhecimentos técnicos e científicos.

Palavras-chaves: 1) Artesanato; 2) Pesquisa Participativa; 3) Design para a Sustentabilidade; 4) Tecnologias Sociais; 5) Empoderamento comunitário.

\section{Introdução}

Garuva pertence à Unidade de Planejamento Regional 6 do Governo do Estado, dista $36 \mathrm{~km}$ de Joinville e abrange uma área de $499,7 \mathrm{~km}^{2}$. Com $60 \%$ da sua área composta da Mata Atlântica, é popularmente conhecida como o "Paraíso das Águas", e se constitui num estratégico manancial hidrológico, onde vivem aproximadamente 11.000 habitantes. Sua economia é predominantemente baseada em atividades primárias, com estabelecimentos rurais e mão-de-obra familiar, sendo que $20 \%$ destes dependem de atividades como a extração ilegal do palmito, madeira e cipó. Mais ou menos 4.000 indivíduos se dedicam direta ou indiretamente ao artesanato destas fibras, com destaque para o vime (Salix spp. SAPINDACEAE) cultivado nas regiões mais frias do Planalto Catarinense, o cipó liaça (Heteropsis rigidifolia Engl - ARACEAE) e o cipó imbé (Philodendron sp. - ARACEAE), ambos extraídos da Mata Atlântica.

O manejo de Produtos Florestais Não-Madeiráveis (PFNM), como é o caso do artesanato de cipó imbé, vem sendo considerado uma opção capaz de aliar conservação com sustentabilidade sócio-ambiental, e devido a um potencial comercial praticamente inexplorado, pode contribuir com as economias familiares e a conservação das

\footnotetext{
1 Este projeto de pesquisa é coordenado pelo professor Douglas Ladik Antunes (douglasantunes@udesc.br), do Curso de Design da UDESC, no âmbito da UDESC, bem como conta com a co-autoria e co-execução da designer industrial e artesão Roberta Tonicelo dos Santos (robertatonicelo@hotmail.com).

Professor do Curso de Design da UDESC.

Empresa de Pesquisa Agropecuária e Extensão Rural de Santa Catarina S.A.
}

DAPesquisa, Florianópolis, v.2, n.4, p. 370-378, 2007. 
diversidades biológica e cultural. Deste modo, a atividade com o cipó imbé foi identificada como uma das ações possíveis dentro dos esforços do Projeto Microbacias 2 (MB2), na medida em que, além da questão ambiental, também pode promover a melhoria da qualidade vida das comunidades envolvidas.

A tradição na extração e beneficiamento do cipó também contribuiu para a proposição deste projeto a partir da participação dos atores sociais envolvidos na cadeia do cipó, aumentando a possibilidade da inclusão de agricultores/artesãos empobrecidos através dum processo orientado para o Desenvolvimento Local Sustentável. A pesquisa participativa, recomendada para este projeto de pesquisa pelo Projeto MB2, representa uma estratégia de legitimação de tomadas de decisão relativas à cadeia produtiva do cipó imbé, pretendendo deflagrar o empoderamento das comunidades aí implicadas.

\section{Metodologia}

A importância do marco metodológico deste projeto estar centrada na pesquisa participativa decorre da necessidade de envolver o saber local com contribuições oriundas dos conhecimentos técnicos e científicos. Neste sentido, a adoção de técnicas geradas a partir do envolvimento direto de artesãos e de pesquisadores foi facilitada, resulando em soluões propostas mútua e simultaneamente. Para Viana (2004):

O processo convencional de tomadas de decisões normalmente não envolve as populações tradicionais de forma efetiva. As decisões sobre políticas e as estratégias de conservação de nossas florestas não respeitam nem incorporam as populações tradicionais como atores-chave para a tomada de decisões coerentes com o ideário da sustentabilidade. Normalmente essa participação tem um caráter cosmético ou utilitarista. No primeiro caso, são feitas reuniões mal organizadas apenas para legitimar decisões tomadas à distância, para garantir uma roupagem mínima exigida por doadores internacionais, governos, etc. No segundo caso, a participação é eficiente na coleta do conhecimento "deles" para o "nosso" projeto. Muito raramente as populações são envolvidas para compartilhar as decisões em todas as etapas de um projeto de intervenção: concepção, implementação e avaliação. Mais raras ainda são as iniciativas que se preocupam em capacitar técnicos e pesquisadores para a utilização de métodos que criem condições para uma participação efetiva, obedeçam um código de ética básico e resultem numa transferência de poder. O resultado é que, raramente, as populações tradicionais são envolvidas no processo de tomada de decisões.

Desta forma, o projeto de pesquisa promoveu a participação e tomadas de decisão em termos de design para a sustentabilidade e tecnologias sociais, associando as competências locais e os conhecimentos técnicos e científicos tanto na análise para as melhorias dos processos produtivos artesanais quanto na adequação das condições ambientais referentes a manufatura destes produtos artesanais. É importante considerar que a gênese deste projeto de pesquisa também resultou dum processo participativo, denominado PEP - Planejamento Estratégico Participativo, realizado pelo Projeto MB2 / EPAGRI, pautando-se, inclusive, em argumentos da Constituição Federal (mais especificamente no Artigo 225 do VI Capítulo):

(...) Todos têm direito ao meio ambiente ecologicamente equilibrado, bem de uso comum do povo e essencial à sadia qualidade de vida, impondo-se ao poder público e à coletividade o dever de defendê-lo e preservá-lo para as presentes e futuras gerações.

A missão da Secretaria Estadual de Educação - SEDUC de Santa Catarina também contribuiu para justificar este projeto, pois assume os seguintes compromissos com a sociedade catarinense:

catarinenses.

Missão: Construir, todos juntos, uma escola pública de qualidade para todos os

Gestão: Desenvolver uma gestão descentralizada, com democracia participativa, trabalhando em equipe e sobrepondo o social ao individual, o público ao privado, o coletivo ao particular, o estratégico ao rotineiro e burocrático.

DAPesquisa, Florianópolis, v.2, n.4, p. 370-378, 2007. 
Desafio: Mais do que administrar a realidade educacional, não se contentar com menos do que mudá-la, para dar um salto de qualidade na educação em Santa Catarina. (grifos do original).

A importância da pesquisa participativa centra-se na pesquisa "com" a comunidade envolvida, diferente da pesquisa "para" a comunidade. Este projeto de pesquisa visou, portanto, a geração de um "novo" conhecimento, caracterizado pela integração do saber local com o conhecimento técnico e científico, resultando, processualmente, numa construção social do conhecimento.

Para Geilfus (1997), os níveis de participação das populações em projetos seguem uma escala crescente de envolvimento em seus processos, e podem ser assim hierarquizados: "Pasividad > Suministro de Información > Participación por Consulta > Participación por Incentivos > Participación Funcional > Participación Interactiva > Auto Desarrollo". Nesse sentido, a comunidade de artesãos de Garuva já se encontra numa fase inicial de Participação Interativa, estando inseridos na Formulação do Problema do projeto de pesquisa desde o início, orientados pelo seguinte conceito de participação:

(...) los grupos locales organizados participan em la formulación, implementación y evaluación del proyecto; esto implica procesos de enseñanza-aprendizaje sistemáticos y estructurados, y la toma de control en forma progresiva del proyecto (...) (Geilfus, 1997:3).

Deste modo, o projeto de pesquisa em questão se desenrola a partir de mecanismos participativos e resultam em propostas de melhorias do design do artesanato manufaturado com tecnologias produtivas sustentáveis, implicando, dentre outras possibilidades, na redução dos aspectos negativos dos respectivos produtos e sua cadeia produtiva. É importante pontuar que esta abordagem também está respalda na série de normas ISO 14000 , que consideram o aspecto ambiental do seguinte modo: "elemento das atividades, produtos ou serviços de uma organização que pode interagir com o meio ambiente".

Conforme apontou o TCC de Tonicelo (2004), várias são as demandas de design e de melhorias de tecnologias sustentáveis à comunidade dos artesãos de Garuva, e entre estas figuram: "(...) necessidade de agilizar os processos de beneficiamento, onde há a geração de resíduos sólidos nos processos de beneficiamento da fibra, emissão de gases tóxicos e poluentes provenientes da queima do enxofre no tratamento antifúngico, dificuldade de secagem do cipó em dias de chuva, desenvolvimento de um produto ou sistema que facilite o transporte dos feixes de cipó, desenvolvimento de ferramentas que facilitem e agilizem os processos de beneficiamento, desenvolvimento de equipamentos de proteção, estimular a criatividade dos artesãos, o desenvolvimento de novos produtos de cipó que agreguem valores ético-estético-formais, desenvolvimento de produtos que objetivem maior qualidade e menor quantidade de peças produzidas, desenvolvimento de identidade visual sócioambiental e desenvolvimento de veículos de comunicação pró-educação ambiental, bem como há falta de organização produtiva e comercial adequada aos artesãos (...)" (2004:9293). Assim, as contribuições de design produzidas neste projeto de pesquisa resultam em êxitos alcançados de um modo muito original: as demandas por design gráfico (identidade visual), por exemplo, foram empreendidas de forma participativa, com a qual se elegeu o nome da associação dos artesãos de cipó imbé de Garuva e os ícones da logomarca através de Oficinas de Criatividade, onde artesãos adultos e suas crianças protagonizaram este processo de trabalho. Outros resultados estão sendo colhidos, ou estão em etapas finais de construção participativa.

Por uma questão de zelo com a dimensão ecológica da sustentabilidade, estabeleceuse uma relação com Núcleo de Pesquisa em Florestas Tropicais - NPFT / UFSC, através da qual se busca maneiras de viabilizar um Plano de Manejo para o cipó imbé de Garuva. Desejava-se com isso levantar as características gerais da área de floresta na área em questão, informações da regeneração e crescimento da espécie, técnicas locais de exploração, normativas de proteção das espécies florestais, critérios de extração e uma projeção dos custos e benefícios deste empreendimento etnobotânico. Destaca-se, entretanto, que esta parceria não foi institucionalizada como parte deste projeto de pesquisa na UDESC. 
Motivados por cuidados especiais com a dimensão social e econômica da sustentabilidade, uma relação foi entabulada com o Núcleo de Estudos e Práticas em Socioeconomia Solidária - NESOL, também da UFSC, que atua na organização social e econômica dos artesãos. Pretende-se, com isto, conhecer à mercadologia deste processo produtivo, com ênfase nos custos de produção, postos de vendas do artesanato e no planejamento estratégico duma entidade que se encarregará desses negócios. Estes trabalhos também não foram institucionalizados como parte deste projeto de pesquisa na UDESC.

Por fim, é relevante que o processo de avaliação dos resultados deste Projeto Farol de Pesquisas Participativas está sendo monitorado pela comunidade de artesãos, extensionistas da EPAGRI, extensionistas do Projeto MB2, Secretaria Municipal de Agricultura de Garuva, UFSC e UDESC.

\section{Algumas das atividades realizadas e alguns dos resultados obtidos até momento}

\subsection{Notas preliminares}

Com o intuito de facilitar a compreensão sobre os resultados obtidos até o momento, alguns aspectos seguem relatados. A saber:

a) Este projeto emergiu do TCC (2004) da então acadêmica do Curso de Design da UDESC, Roberta Tonicelo, dando diversas pistas de demandas da comunidade de artesãos e indicando o "design sistema-objeto", (Manzini \& Vezolli, 2002), ou "design para sustentabilidade", como a tipologia mais adequada para este projeto de pesquisa.

b) O projeto foi estruturado por um grupo de professores da UDESC e da UFSC, pesquisadores da EPAGRI / Projeto Microbacias II e pesquisadores independentes ${ }^{4}$. A maior contribuição dos pesquisadores da EPAGRI / Projeto Microbacias II se deu no âmbito do "Curso de Capacitação em Pesquisas Participativas" / Governo do Estado, coordenado pelo Prof. Dr. De Boeff (consultor internacional) e o Prof. Dr. Sergio Pinheiro, da EPAGRI. Parte da equipe se envolveu nesta capacitação. A metodologia geral adotada é a dos "Agricultores [Artesãos] Experimentadores", testada na África anteriormente e adotada no âmbito desta capacitação. Este processo de capacitação, ainda em andamento, estimulou a elaboração dos dez "Projetos Faróis" do Estado, e seguem avaliados pelo Prof. Dr. Sergio Pinheiro e pesquisadores das equipes desses Projetos, organizados numa Comissão de sistematização das experiências (Holliday, 2006) dos mesmos.

c) Entre os Projetos Faróis de Pesquisa Participativa este é o único que focalizou uma cadeia produtiva.

d) Uma versão ampliada deste projeto foi recentemente contemplada com financiamento pelo Edital Universal da FAPESC, tendo como coordenador geral o Prof. Dr. Armando Lisboa / NESOL UFSC.

f) A EPAGRI também apoiou institucional e financeiramente este projeto de pesquisa.

É importante mencionar ainda, que a equipe de pesquisadores deste projeto assumiu a interdisciplinaridade (em termos de design, engenharia mecânica e ambiental, botânica e socioeconômica) e a transdisciplinaridade (Basarab, 1999) da equipe em relação ao "saber local" dos agricultores/artesãos e demais atores sociais de Garuva. Desta forma, algumas premissas deste Projeto são manifestas, para melhor expor a sua base conceitual e as atividades realizadas. Dada a importância estratégica dessas, algumas delas seguem citadas para subdisiar uma melhor compreensão dessas atividades realizadas e expostas neste artigo.

De modo geral, este projeto pretende ser uma "sementinha" de um processo de Desenvolvimento Local Sustentável. Em termos de design, pretendeu-se alcançar a materialidade de um produto que sintetize prudência no extrativismo sustentável dos recursos naturais/matérias-primas do artesanato (Manejo Sustentável), evitando prejuízos

\footnotetext{
As botânicas Renata Zambonim e Silvia Venturi, o agrônomo e pesquisador da EPAGRI Fábio Zambonim, o economista da UFSC Prof. Dr. Armando Lisboa e o Administrador de Empresas Paulo Antunes Grijó.
} 
desnecessários para o ecossistema e a cultura local. Além disso, a cadeia produtiva do artesanato de cipó imbé demanda aperfeiçoamento de ferramentas de manufatura e processos produtivos, orientando-os para uma melhor equação dos resíduos ali gerados, e o desafio de adequar a segurança e higiene do trabalho. Todos estes aspectos estão vinculados à uma cultura organizacional de produção e comercialização fundamentada na autonomia e autogestão dos artesãos, ou um "empreendimento de economia solidária" (Gaiger, 2003).

Assim, alguns argumentos científicos que serviram à concepção do projeto seguem citados, para explicitar a composição da equipe de trabalho e respectivas atribuições. A subequipe de Manejo Sustentável considerou:

"O processo convencional de tomadas de decisões normalmente não envolve as populações tradicionais de forma efetiva. As decisões sobre políticas e as estratégias de conservação de nossas florestas não respeitam nem incorporam as populações tradicionais como atores-chave para a tomada de decisões coerentes com o ideário da sustentabilidade. Normalmente essa participação tem um caráter cosmético ou utilitarista. No primeiro caso, são feitas reuniões mal organizadas apenas para legitimar decisões tomadas à distância, para garantir uma roupagem mínima exigida por doadores internacionais, governos, etc. No segundo caso, a participação é eficiente na coleta do conhecimento 'deles' para o 'nosso' projeto. Muito raramente as populações são envolvidas para compartilhar as decisões em todas as etapas de um projeto de intervenção: concepção, implementação e avaliação. Mais raras ainda são as iniciativas que se preocupam em capacitar técnicos e pesquisadores para a utilização de métodos que criem condições para uma participação efetiva, obedeçam um código de ética básico e resultem numa transferência de poder. O resultado é que, raramente, as populações tradicionais são envolvidas no processo de tomada de decisões" (Viana, 2004).

A Subequipe de Tecnologias Produtivas Sustentáveis, e de design, foi instruída pelo conceito de Tecnologias Sociais (TS), e é determinante à inclusão do saber local. A definição de TS é a seguinte:

"Conjunto de técnicas e metodologias transformadoras, desenvolvidas e/ou aplicadas na interação com a população e apropriadas por ela, que representam soluções para inclusão social e melhoria das condições de vida" (Instituto de Tecnologia Social, 2004).

\section{E os respectivos princípios:}

“- Aprendizagem e participação são processos que caminham juntos: aprender implica participação e envolvimento; e participar implica aprender;

- A transformação social implica compreender a realidade de maneira sistêmica: diversos elementos se combinam a partir de múltiplas relações para construir a realidade;

- A transformação social ocorre na medida em que há respeito às identidades locais: não é possível haver transformação se não a partir das especificidades da realidade existente; e

- Todo indivíduo é capaz de gerar conhecimento e aprender: a partir do momento que está inserido numa cultura e em contato com o mundo, todo indivíduo produz conhecimento e aprende a partir dessa interação" (Idem, 2004).

Já a cultura organizacional foi baseada no Comércio Justo e Solidário (Jonhson, 2004), é oriunda da Socioeconomia Solidária, tendo por base que

"Os empreendimentos econômicos solidários compreendem diversas modalidades de organização econômica, originadas da livre associação de trabalhadores, com base em princípios de autogestão, cooperação, eficiência e viabilidade. Aglutinando indivíduos excluídos do mercado de trabalho (...) à procura de alternativas coletivas de sobrevivência. (...) Apresentam-se sob a forma de grupos de produção, cooperativas e empresas de autogestão e combinam suas atividades econômicas com ações de cunho educativo e cultural, valorizando o sentido da comunidade de trabalho e o compromisso com a coletividade social em que se inserem" (Gaiger, 2003).

"Para a economia solidária o ato de consumir não é apenas econômico, é também ético e político. É um exercício de poder pelo qual efetivamente podemos apoiar a não exploração de seres humanos, a não destruição progressiva do planeta, a não concentração de riquezas e a não exclusão social (...)" (Blauth, 2006). 
Pelo exposto é possível compreender que, além das intervenções pontuais de design previstas no projeto de pesquisa (como planejamento de identidade visual, de tag, de catálogo de produtos, família de produtos, etc.), operou-se com a orientação do "design sistema-objeto" (Manzini, 2002), ou "design para a sustentabilidade", com o seguinte conceito:

\footnotetext{
"Design é uma atividade criativa, cujo objetivo é estabelecer qualidades múltiplas a objetos, processos, serviços e seus sistemas em todo ciclo de vida. Todavia, design é o fator central de humanização inovativa de tecnologias e o fator crucial da substituição cultural e econômica. (...) procura descobrir e investigar relações estruturais, organizacionais, funcionais, expressivas e econômicas, com o intuito de:

- Aumentar a sustentabilidade global e proteção ambiental (ética global);

- Prover benefícios e liberdade a toda comunidade humana, individual e coletiva, usuários finais, produtores e protagonistas de mercado (ética social);

- Apoiar a diversidade cultural apesar do processo de globalização mundial (ética cultural);e

- Fornecer produtos, serviços e sistemas, com aquelas formas que são expressivas (semiótica) e coerentes com sua complexidade (estética)" (ICSID - Conselho Mundial de Sociedades de Design Industrial, 2002).
}

Assim, os resultados conquistados até o momento ensejam uma autoria coletiva (direito difuso) de todos os protagonistas envolvidos neste projeto.

\subsection{Algumas atividades realizadas e alguns resultados obtidos}

a) Co-apresentação do "Projeto Cipó Imbé", como uma demanda dos próprios artesãos. Co-exposição do contexto e arranjo institucional do projeto. Co-exposição dos objetivos e estrutura do projeto. Apresentação da subequipe de Manejo Sustentado, com exposição de questões legais, do que é um Plano de Manejo, da necessidade de se levantar informações para o Plano de manejo, da inclusão do cipó imbé no portifólio do Ministério do Meio Ambiente - MMA (através do congresso nacional "Plantas do Futuro", realizado pelo MMA e a UFSC), e do respectivo plano de ação. Co-apresentação da subequipe de Design e Tecnologias Produtivas Sustentáveis, com a exposição dos conceitos adotados, exposição de experiências similares, dos métodos de trabalho, e do respectivo plano de ação. Coapresentação da subequipe de Economia Solidária, com explanação sobre a formação de grupos de trabalho, métodos de trabalho, critérios de participação e demais atores locais. Co-condução do processo participativo (Geilfus, 1997) de composição dos grupos de Agricultores/Artesões Experimentadores, resultando no Grupo de Trabalho de Manejo Sustentado (composto por Ruth, Antonio Rocha e seu filho, Marlene, Judith e Euclydes), no Grupo de Trabalho de Design e Tecnologias Produtivas Sustentáveis (composto por Maria Clanilce, Ricardo, Zezinho, Judith, João da Silva Santos e Patrícia), e da Grupo Trabalho de Economia Solidária (composto por Ivo Tondorf, Ricardo, Carlos Hirnaski, Marlene Estevão, Maria Gonçalves e Maria Fernandes).

b) Co-planejamento e reunião de refinamento de conteúdos, técnicas participativas e abordagens utilizadas na dinâmica "Linha do Tempo" (Geilfus, 1997), que reconstruiu o percurso histórico do artesanato de cipó imbé em Garuva. Assessoramento à construção da Linha do Tempo, pelos artesãos, e demais atores sociais. Esta atividade considerou: a) a organização dos grupos de trabalho, b) o apoio metodológico (facilitadores) e a mediação dos debates mais "fortes", c) a marcação dos eventos históricos mais importantes em tarjetas, d) a inserção de comentários dos protagonistas da dinâmica como legenda.

c) Entrega e co-explanação dos resultados tabulados na "Linha do Tempo". Apoio à atividade de priorização das ferramentas de manufatura do artesanato de cipó imbé. Coexplanação do processo de trabalho de design a ser iniciado, incluindo: a 1a Definição do problema; Coleta de informações sobre o "cliente", produtos e públicos consumidores; Análise, interpretação e organização da informação obtida (ou 2 ${ }^{a}$ Definição do problema); Determinação de objetivos; Especificações para visualização (ou 3 ${ }^{a}$ Definição do problema); 
Desenvolvimento de anteprojeto; Organização da produção; Implementação; e Avaliação do grau alcance dos objetivos estabelecidos (Frascara, 1999). E apresentação de exemplos de produtos de design integrantes de projetos de pesquisas similares. Apoio à atividade de levantamento de problemas e potencialidades relacionados com as ferramentas de manufatura, e á priorização destas pelos artesãos. Co-registro fotográfico dos produtos de cipó Imbé existentes. Co-apresentação e co-moderação dos debates após exibição do vídeo sobre a experiência de Economia Solidária de Palmas / CE. Co-explanação de princípios de economia solidária. Moderação sobre os trabalhados de design a serem feitos (identidade visual, tag com o perfil dos artesãos e procedência dos produtos, etc.). Apoio à moderação dos debates para priorizar participativamente as técnicas e tecnologias a serem aprimoradas no processo produtivo do artesanato de cipó imbé. Exposição sobre o que é design, as etapas que compõe um projeto desse tipo, o que é qualidade, e os aspectos culturais locais que podem valorizar o artesanato de cipó imbé. Exposição da importância das embalagens e da identidade visual como fator de melhoria de comercialização. Apresentação do vídeo a "Revolução do Consumo", com a história das atividades da cooperativa de produtos de limpeza "PalmaLimpe" e da cooperativa de costureiras "PalmaFashion", e de como foram desenvolvidos o design destes produtos de "empreendimentos de economia solidária" e as respectivas formas de comercialização. Exposição de alguns fundamentos da Economia Solidária e de possíveis alternativas de organização da produção e comercialização do artesanato. Apresentação de marcas, folders e outros impressos de iniciativas similares de outras comunidades, tais como: Arte Baniwa (AM), Fibrarte (PE), Boutique Solidária (PR), e outras. Desenho participativo do esquema atual de comercialização do artesanato de cipó Imbé em Garuva, resultando no seguinte:

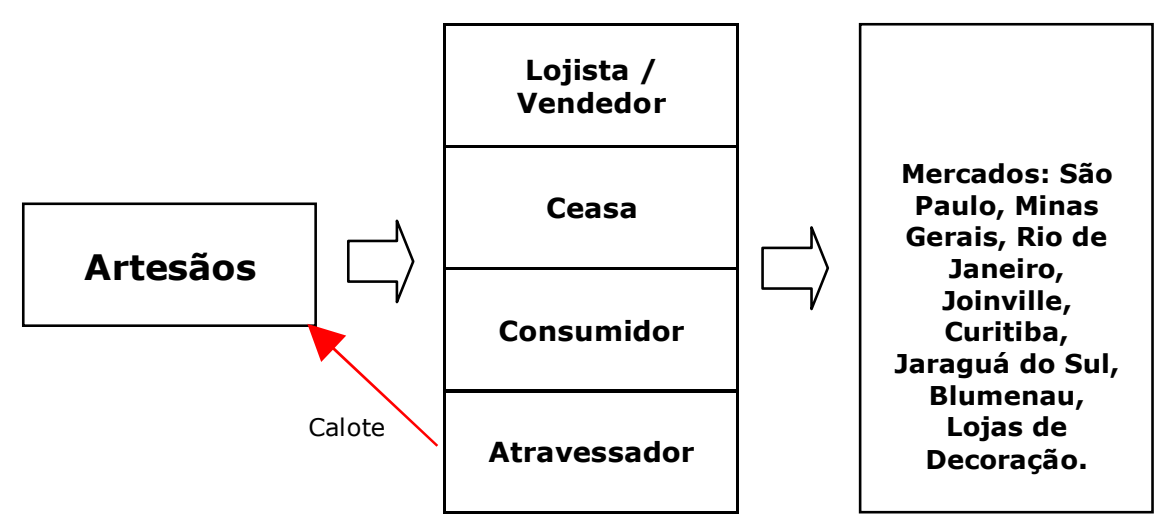

d) Co-planejamento da reunião interinstitucional com as entidades parceiras do projeto de pesquisa (EPAGRI, Associação de Desenvolvimento da Microbacia de Palmital, Prefeitura de Garuva, UFSC, etc.), onde se relatou as atividades realizadas e respectivos custos financeiros, definido-se, então, as metas de curto prazo do projeto, o plano de cadastramento dos artesãos de cipó imbé de Garuva (incluindo coleta de informações primárias relativas a dados sócio-econômicos e ambientais) e a estratégia de comunicação para tanto. Co-planejamento das mensagens de veiculação deste cadastramento para a Rádio União Comunitária. Co-planejamento e apoio na realização de dinâmicas participativas para se compreender a visão do "que é qualidade de vida para eles", quais as expectativas deles em relação ao projeto de pesquisa em 2006-2, e quais seriam as contribuições deles na execução do mesmo. Para tanto realizou-se: a) Construção da "Árvore da Qualidade de Vida" (cujos "frutos" representam o mais importantes para eles ou a idéia deles de qualidade de vida); b) "Visão do D", a partir da metáfora da letra d que também é um b (dependendo do ponto de vista do observador), para demonstrar a diferença entre os pontos de vista dos protagonistas do projeto e a necessidade de interação em torno duma visões e "concertação" (Zapata, 2007) de um "projeto" comum; c) "Relato das Mãos", com o desenho das próprias mãos na frente e no verso dum papel, promovendo o propósito 
de unir uma das mãos em torno das expectativas de curto prazo, e a outra em torno da construção social do "projeto comum".

e) Planejamento e co-levantamento fotográfico dos produtos artesanais de cipó Imbé de Garuva (ou levantamento de dados do planejamento gráfico do catálogo de produtos artesanais de cipó imbé de Garuva). Co-planejamento da planilha de acompanhamento e de controle de produção do artesanato.

f) Continuação do co-planejamento gráfico do catálogo de produtos artesanais de cipó imbé de Garuva (ou análise de dados). Participação no Curso de Extensão "Introdução aos Processos Participativos", ministrado pelo Dr. João Carlos Canuto (EMBRAPA Campinas, SP). Co-publicação de poster do "Projeto Cipó imbé", no Congresso Nacional de Etnobiologia, realizado em Porto Alegre / RS.

g) Co-publicação de artigos científicos relacionados com o tema deste projeto de pesquisa.

\subsection{Atividades em estágio de finalização}

Este projeto de pesquisa tem previsão de encerramento fixado em dezembro de 2007, e, até lá, ainda serão concluídas algumas atividades pontuais de design. A saber:

a) Pré-produção do catálogo de produtos artesanais de cipó imbé de Garuva;

b) Acompanhamento da impressão gráfica (pela EPAGRI) dos catálogos de produtos artesanais de cipó imbé de Garuva;

c) Acompanhamento da impressão gráfica (pela EPAGRI) dos tags de identificação dos artesãos e dos respectivos produtos artesanais de cipó imbé de Garuva;

d) Conclusão da concepção de uma nova família de produtos; e

e) Avaliação - participativa - deste projeto de pesquisa para a comunidade de artesãos de cipó imbé de Garuva.

\section{Considerações finais}

A cultura de projetos de pesquisa participativa e as respectivas abordagens inter e transdisciplinares, envolvendo as áreas de conhecimento de design e tecnologias sociais, é incipiente em Santa Catarina, e as entidades produtoras e promotoras do conhecimento técnico e científico parecem não compreenderem o expressivo potencial destes. Embora os resultados obtidos até o momento ainda estejam incompletos - pois que estão num estágio inicial - , são animadores, mesmo conquistados mais por força de vontade pessoal dos pesquisadores e atores sociais envolvidos no projeto de pesquisa que pelo ambiente de trabalho profissional oportunizado à sua consecução. Os parcos recursos financeiros aprovados para ele não foram integralmente desembolsados, desrespeitando os compromissos e cronograma do projeto com motivos nunca devidamente explicados.

Todavia, estes primeiros resultados caracterizam um processo de pesquisa, extensão e ensino indivizível, com data para começar e sem data para encerrar, já que os processos de desenvolvimento local sustentável se seguem numa cadeia de pequenos resultados de um mosaico que conforma a "qualidade de vida" das comunidades envolvidas. O que se pode inferir, então, com a cautela que pesquisas em estágios embrionários suscitam, é que a pobreza do contexto sócio, econômico e ambiental dos artesãos e do artesanato de cipó imbé de Garuva não se justifica, denotando, enfim, que o combate a este tipo de patologia sócio, econômica e ambiental demanda atenção e mais iniciativas deste tipo no Estado.

Entretanto, mesmo com um financiamento irrisório - dez mil reais para dois anos, e dois mil e quinhentos reais de fato desembolsados - , este projeto de pesquisa produziu uma mobilização social dos artesãos surpreendente, demonstrando grande potencial para o 
empoderamento comunitário dos artesãos de cipó imbé de Garuva, através do design para a sustentabilidade e tecnologias sociais, ainda que demandem mais aperfeiçoamentos técnicos e científicos e mais experiências práticas para consagrá-los como instrumento estratégico de (i) combate a pobreza e exclusão social de comunidades detentoras de saberes locais importantes da cultura tradicional catarinense, (ii) de estimular um desenvolvimento harmonioso destes saberes locais e conhecimentos técnicos e científicos necessários para se conservar a biodiversidade do Estado, (iii) de potencializar a educação de um design inter e transdisciplinar e tecnologias sociais como mais uma frente de vanguarda científica e tecnológica na UDESC (em parceria com a EPAGRI e UFSC) e, finalmente, (iv) de promover uma imagem qualificada da UDESC e do Estado de Santa Catarina.

\section{Blibliografia citada}

BASARAB, Nicolescu. O manifesto da transdisciplinaridade. São Paulo: Trion, 1999.

BLAUTH, Guilherme. De olho na vida: reflexões para um consumo ético. Florinanópolis: Instituto Harmonia da Terra, 2006.

FRASCARA, Jorge. Diseño gráfico e comunicación. Buenos Aires: Infinito, 2000.

GAIGER, Luiz Inácio. In: Empreendimentos econômicos solidários. A outra economia / Antonio David Cattani (Org.). Porto Alegre: Veraz, 2003.

GEILFUS, F. 80 herramientas para el desarollo participativo. São Salvador: ProchalateIICA, 1997.

HOLLIDAY, Oscar Jara. Para sisteatizar experiências. Brasília: MMA, 2006.

INSTITUTO DE TECNOLOGA SOCIAL. Tecnologia Social no Brasil: Direiro à ciência e ciência para a cidadania. São Paulo: Instituto de Tecnologa Social / Ministério de Ciência e Tecnologia, 2004.

JONHSON, Pierre W. Comércio Justo e Solidário. São Paulo: Instituto Pólis, 2004. MANZINI, Ezio; VEZZOLI, Carlo. O Desenvolvimento de Produtos Sustentáveis. São Paulo: USP, 2002.

ZAPATA, Tania. Desenvolvimento teritorial a distância. Florianópolis: SEad/UFSC, 2007. 